\title{
FAST TURBULENT DEFLAGRATION AND DDT OF HYDROGEN-AIR MIXTURES IN SMALL OBSTRUCTED CHANNEL
}

\author{
Teodorczyk A., Drobniak P. and Dabkowski A. \\ Warsaw University of Technology, ITC, Nowowiejska 21/25, 00-665 Warszawa, Poland, e-mail: \\ ateod@itc.pw.edu.pl
}

\begin{abstract}
An experimental study of flame propagation, acceleration and transition to detonation in hydrogen-air mixture in $2 \mathrm{~m}$ long rectangular cross section channel filled with obstacles located at the bottom wall was performed. The initial conditions of the hydrogen-air mixture were $0.1 \mathrm{MPa}$ and $293 \mathrm{~K}$. Three different cases of obstacle height (blockage ratio $0.25,0.5$ and 0.75 ) and four cases of obstacle density were studied with the channel height equal to $0.08 \mathrm{~m}$. The channel width was $0.11 \mathrm{~m}$ in all experiments. The propagation of flame and pressure waves was monitored by four pressure transducers and four in house ion probes. The pairs of transducers and probes were placed at various locations along the channel in order to get information about the progress of the phenomena along the channel. To examine the influence of mixture composition on flame propagation and DDT the experiments were performed for the compositions of $20 \%, 25 \%$ and $29.6 \%$ of $\mathrm{H}_{2}$ in air by volume. As a result of the experiments the deflagration and detonation regimes and velocities of flame propagation in the obstructed channel were determined.
\end{abstract}

\section{INTRODUCTION}

Flames propagating in tubes and channels in the turbulence field created by obstructing obstacles are studied intensively in last decades both experimentally and numerically. The reason for the interest has to do with concerns related to safety. It has invariably been observed that if a combustible gas mixture is not too close to the flammability limits, then a flame propagating in an obstacle field can accelerate very rapidly to high supersonic velocities. Such high speed flames can drive shock waves with substantial overpressures. If the mixture is sufficiently sensitive, the highly accelerated flame may even undergo transition to detonation.

Channels with obstacles are often used to study the flame acceleration and DDT in a controlled manner [1-14]. Considerable effort has been devoted to identifying the range of phenomenological behaviour of such flames and to deciphering the underlying mechanisms. Regimes of propagation have been classified and some attempts have been made to quantify limiting criteria responsible for the existence of the different regimes. From the practical point of view, the most important aspects of the accelerated flame phenomenon have to do with the steady-state propagation of very high speed flames, transition to detonation and propagation of sub-Chapman-Jouget detonations (quasidetonations).

With regard to high speed flames it has been observed that a flame propagating in a continuous obstacle field will accelerate very rapidly and will reach a terminal, and on the average, steady-state velocity, which it will then maintain for the rest of its passage over the obstacles. If the mixture is not too close to the flammability limits, the steady-state flame propagation velocity will approach the 
speed of sound of the combustion products. Extensive evidence now indicates that this level of flame velocity appears to be the maximum achievable by a turbulent flame in the non-detonative mode of combustion. Because of these observations it has been suggested that such maximum flame speed is prescribed and limited gas dynamically by the process of frictional and thermal choking. Although this is a plausible explanation in the light of the observed behaviour, there has not been any more direct evidence. For example, it is not known whether it is the flame which drives itself to such high speed or that it is sustained by the precursor shock wave and wave interaction over the obstacles ahead of the flame.

The mechanisms underlying the propagation of sub-CJ detonations are also not understood at the present time. One school of thought suggests that it is the hot spots created by shock reflections at the obstacles that sustain the sub-CJ, detonation-like propagation, hence "quasi-detonations". The other point of view is that a steady state CJ detonation is retarded by momentum losses in its propagation over the obstacles. However, the precise way in which this might occur is not understood.

The present study was motivated by the recent advanced computer simulations of flame acceleration and transition to detonation in hydrogen-air mixture in obstructed channels by Gamezo et al. [15]. We have performed our systematic study for the same geometry and initial conditions in order to generate data for the validation of past and future simulations. The main objectives were to determine flame propagation regimes and velocities as a function of blockage ratio, obstacle spacing and hydrogen-air mixture equivalence ratio in narrow rectangular channel.

\section{EXPERIMENTAL}

Flame propagation in hydrogen-air mixture was studied in $2 \mathrm{~m}$ long rectangular cross section channel filled with obstacles located at the bottom wall. The initial conditions of the hydrogen-air mixture were $0.1 \mathrm{MPa}$ and $293 \mathrm{~K}$. The channel width was $0.11 \mathrm{~m}$ and its height $H$ was $0.08 \mathrm{~m}$. Three values of mixture equivalence ratio $\Phi$ were used: $0.6,0.8$ and 1.0. Three different obstacle heights $h$ were tested: $0.02 \mathrm{~m}, 0.04 \mathrm{~m}$ and $0.06 \mathrm{~m}$ (blockage ratio $\mathrm{BR}=0.25,0.5$ and 0.75 , respectively). Four different cases of obstacle spacing $L$ were used: no obstacles, $0.08 \mathrm{~m}, 0.16 \mathrm{~m}$ and $0.32 \mathrm{~m}$. The geometry of channel with obstacles is schematically shown in Fig.1. Mixture was ignited by weak electric spark at one end of the channel.

The propagation of flame and pressure waves was monitored by four pressure transducers and four ion probes. The pairs of transducers and probes were placed at locations along the channel shown in Fig.2.

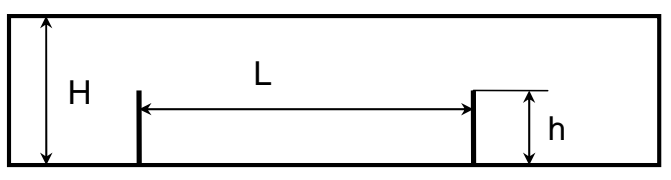

Figure1. Schematic of channel geometry

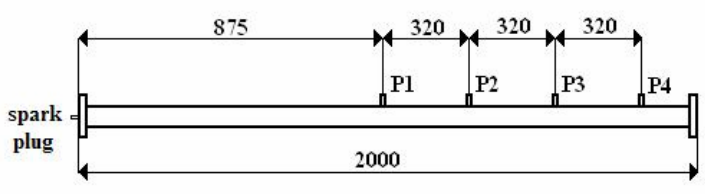

Figure 2. Location of pressure transducers and ion probes 
Figure 3 shows the schematic of experimental facility and Fig. 4 presents the view of obstacles and the channel.

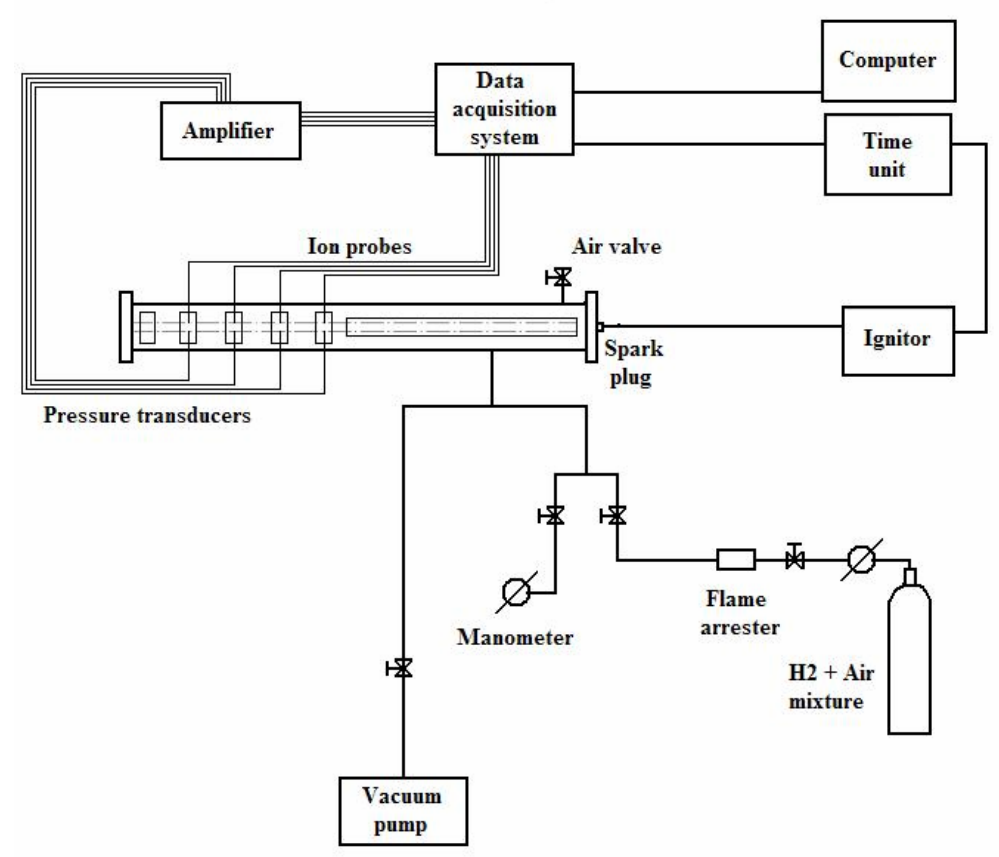

Figure 3. Schematic of the experimental setup

\section{INFLUENCE OF BLOCKAGE RATIO OBSTACLE DENSITY AND MIXTURE REACTIVITY}

Four values of blockage ratio BR were studied: $0,0.25,0.5$ and 0.75 . Figure 5 shows the average flame velocity along the tube for stoichiometric mixture and largest distance between obstacle $L=320$ $\mathrm{mm}$. Transition to detonation was observed for blockage ratio 0.25 and 0.5 . For the smooth channel without obstacles only turbulent deflagration regime was achieved with the velocity of about $450 \mathrm{~m} / \mathrm{s}$. Similarly, for the high blockage ratio of 0.75 also fast deflagration with the velocity of the order of $1000 \mathrm{~m} / \mathrm{s}$ was observed. Similar results were obtained for denser obstacles configuration $L=160 \mathrm{~mm}$ (Fig.6): DDT for $\mathrm{BR}=0.25$ and $\mathrm{BR}=0.5$ and fast deflagration for $\mathrm{BR}=0.75$ (average velocity of 700 $\mathrm{m} / \mathrm{s}$ ). With denser obstacles the velocity of fast deflagration was lower due to larger momentum losses.

Tables 1-3 give details of the flame propagation regimes and velocities observed in all cases of equivalence ratio and obstacle density for three values of blockage ratio. At low blockage ratio (BR = 0.25 ) DDT was observed for $\Phi=0.8$ and $L=160$. This was optimum obstacle density for this case, higher and lower obstacle densities resulted in fast deflagration regime only with the flame velocity 
close to sound speed in combustion products (Table 4). At medium blockage ratio $(B R=0.5)$ the optimum obstacle density for the detonation hazard was closer to $\mathrm{L}=320 \mathrm{~mm}$. At high blockage ratio $(\mathrm{BR}=0.75)$ only fast deflagration regime of flame propagation was observed for all cases.

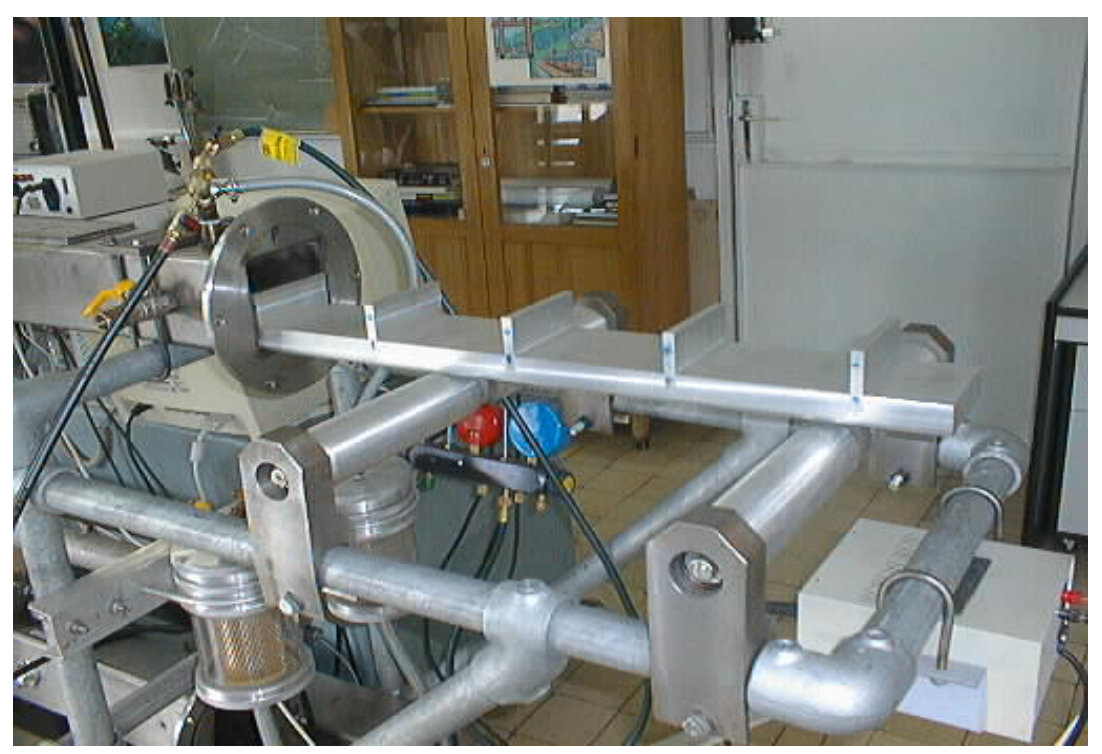

Figure 4. The view of obstacles and the channel

Table 4 gives the values of $\mathrm{CJ}$ detonation velocity, sound speed in combustion products and cell size for the hydrogen-air mixtures studied in this work.

Table 1. Flame propagation regimes and velocities for blockage ratio $\mathrm{BR}=0.25$; FD - Fast Deflagration; DDT - Transition to Detonation; DET - Detonation

\begin{tabular}{|l|l|l|l|}
\hline$\Phi$ & $\mathrm{L}=80 \mathrm{~mm}$ & $\mathrm{~L}=160 \mathrm{~mm}$ & $\mathrm{~L}=320 \mathrm{~mm}$ \\
\hline 0.6 & & FD & FD \\
& & $500 \mathrm{~m} / \mathrm{s}$ & $600 \mathrm{~m} / \mathrm{s}$ \\
\hline 0.8 & & DDT & FD \\
& & & $1000 \mathrm{~m} / \mathrm{s}$ \\
\hline 1.0 & & DET & DDT \\
& & $1900 \mathrm{~m} / \mathrm{s}$ & \\
\hline
\end{tabular}

Table 2. Flame propagation regimes and velocities for blockage ratio $\mathrm{BR}=0.5$

\begin{tabular}{|l|l|l|l|}
\hline$\Phi$ & $\mathrm{L}=80 \mathrm{~mm}$ & $\mathrm{~L}=160 \mathrm{~mm}$ & $\mathrm{~L}=320 \mathrm{~mm}$ \\
\hline 0.6 & & FD & FD \\
& & $650 \mathrm{~m} / \mathrm{s}$ & $600 \mathrm{~m} / \mathrm{s}$ \\
\hline 0.8 & & FD & DDT \\
& & $900 \mathrm{~m} / \mathrm{s}$ & \\
\hline 1.0 & & DDT & DET \\
& & & $2000 \mathrm{~m} / \mathrm{s}$ \\
\hline
\end{tabular}


Table 3. Flame propagation regimes and velocities for blockage ratio $\mathrm{BR}=0.75$

\begin{tabular}{|l|l|l|l|}
\hline$\Phi$ & $\mathrm{L}=80 \mathrm{~mm}$ & $\mathrm{~L}=160 \mathrm{~mm}$ & $\mathrm{~L}=320 \mathrm{~mm}$ \\
\hline 0.6 & FD & FD & FD \\
& $550 \mathrm{~m} / \mathrm{s}$ & $500 \mathrm{~m} / \mathrm{s}$ & $500 \mathrm{~m} / \mathrm{s}$ \\
\hline 0.8 & FD & FD & FD \\
& $600 \mathrm{~m} / \mathrm{s}$ & $650 \mathrm{~m} / \mathrm{s}$ & $900 \mathrm{~m} / \mathrm{s}$ \\
\hline 1.0 & FD & FD & FD \\
& $700 \mathrm{~m} / \mathrm{s}$ & $700 \mathrm{~m} / \mathrm{s}$ & $950 \mathrm{~m} / \mathrm{s}$ \\
\hline
\end{tabular}

Table 4. CJ detonation velocity, sound speed in combustion products and cell size for hydrogen-air at $0.1 \mathrm{MPa}$ initial pressure and 293K [16,17]

\begin{tabular}{|l|l|l|l|}
\hline$\Phi$ & $\mathrm{V}_{\mathrm{CJ}}[\mathrm{m} / \mathrm{s}]$ & $\mathrm{a}_{\mathrm{CP}}[\mathrm{m} / \mathrm{s}]$ & $\lambda[\mathrm{mm}]$ \\
\hline 0.6 & 1709 & 974 & 40 \\
\hline 0.8 & 1866 & 1045 & 13 \\
\hline 1.0 & 1971 & 1092 & 8 \\
\hline
\end{tabular}

Figure 7 shows the pressure profiles and ion probe voltage profiles versus time at four locations along the channel (Fig.2) for the $\mathrm{L}=320 \mathrm{~mm}, \mathrm{BR}=0.25$ and $\Phi=1$. Two first plots show fast deflagration regime with characteristic separation between leading shock and flame front. The third picture shows transition to detonation phase with very high pressure peak reaching $7 \mathrm{MPa}$ and the last picture shows overdriven detonation slowly decaying to CJ conditions after DDT.

Figure 8 shows the comparison of pressure profiles (black) and ion probe voltage signals (red) in time at the same location (P3) along the channel for two mixture compositions (left - $\Phi=0.8$ and right $\Phi=1)$. In lean hydrogen-air mixture $(\Phi=0.8)$ the fast deflagration regime of flame propagation is visible with distinct separation between leading shock wave and flame front. In stoichiometric mixture slightly overdriven detonation is visible with shock wave and flame front merged and pressure peak of $3 \mathrm{MPa}$.

Figure 9 shows the comparison of pressure profiles (black) and ion probe voltage signals (red) in time at the same location (P4) along the channel for two mixture compositions (left - $\Phi=0.6$ and right - $\Phi$ $=0.8)$. In the very lean hydrogen-air mixture $(\Phi=0.6)$ the turbulent deflagration regime of flame propagation is visible with large separation between first pressure wave and flame front. In more reactive mixture the highly overdriven detonation close after DDT is visible with shock wave and flame front merged and pressure peak of more than $4 \mathrm{MPa}$. 


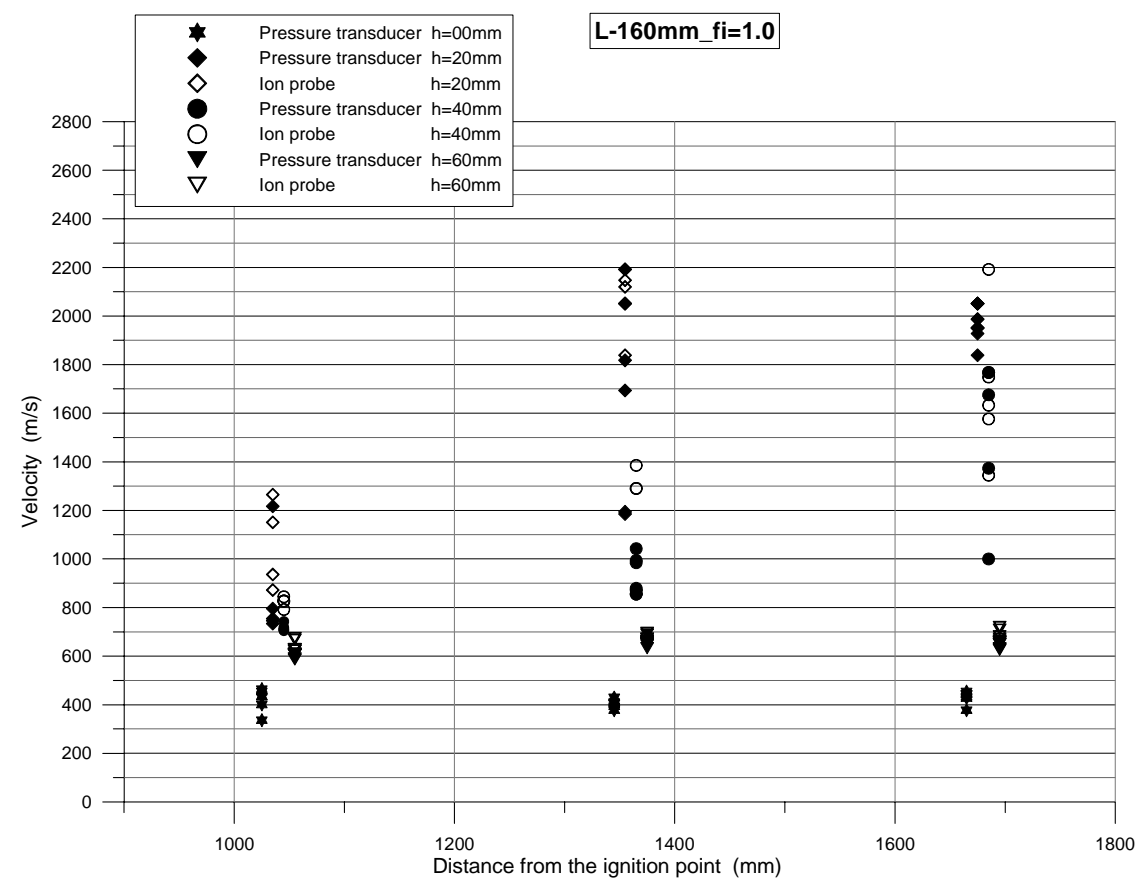

Figure 5. Average velocity of flame (open) and pressure wave (solid) for $\mathrm{L}=320 \mathrm{~mm}$

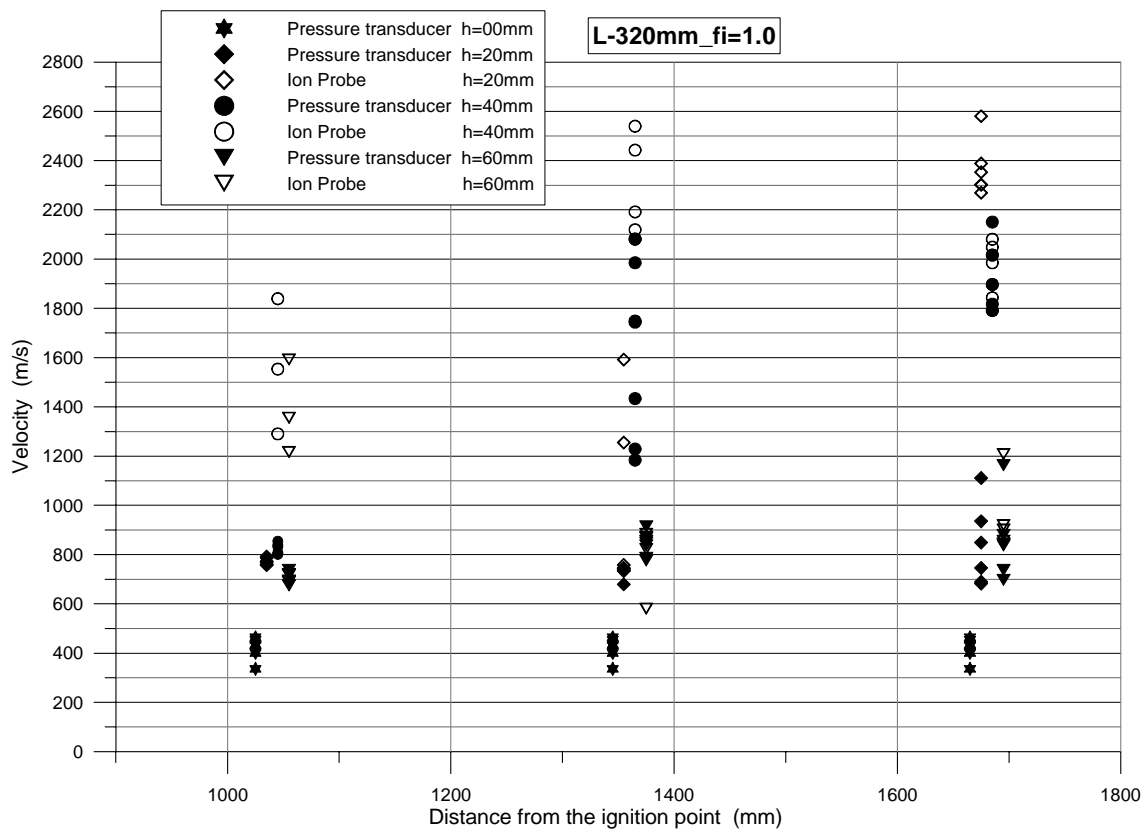

Figure 6. Average velocity of flame (open) and pressure wave (solid) for $\mathrm{L}=160 \mathrm{~mm}$ 

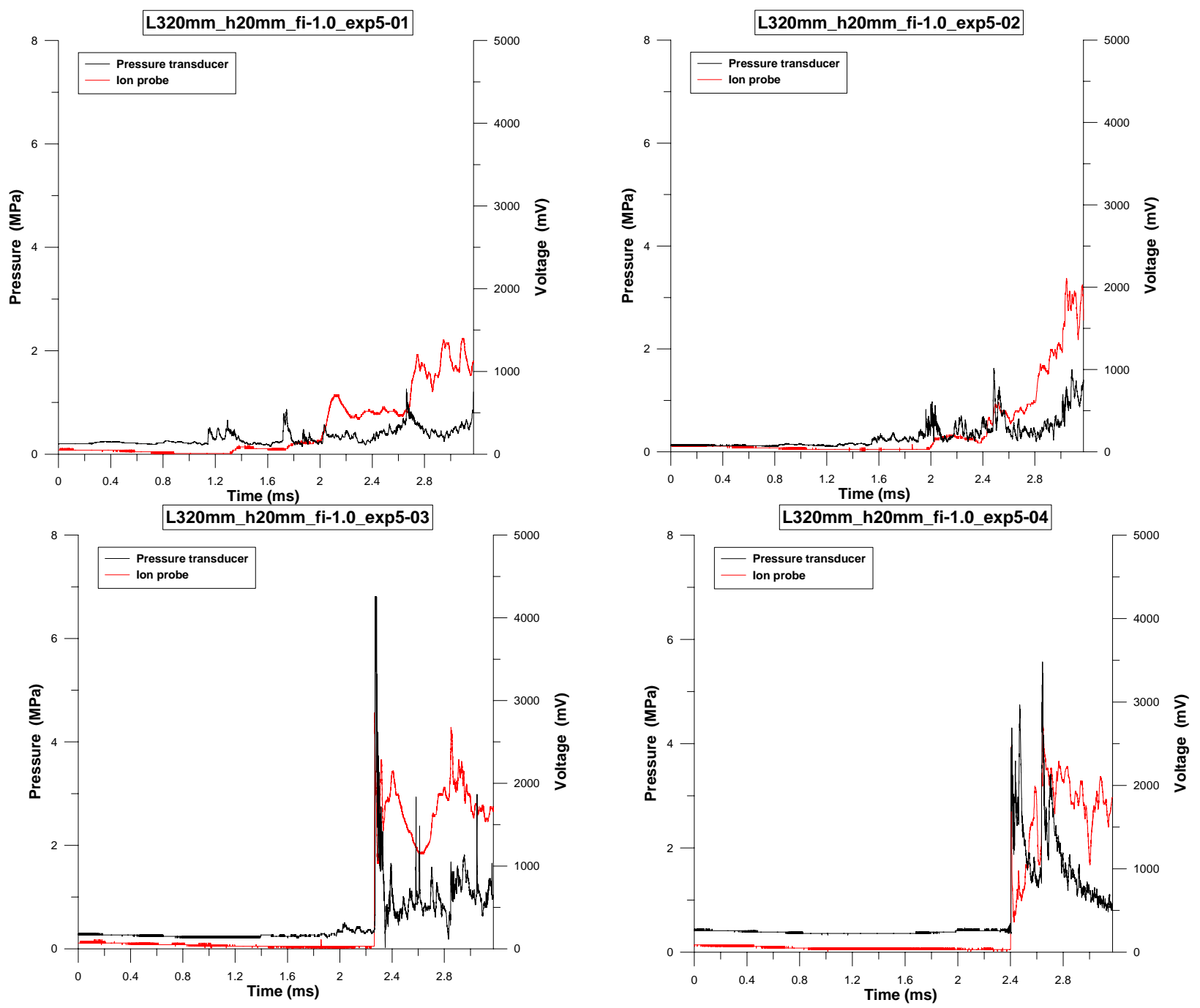

Figure 7. Pressure profiles (black) and ion probe voltage profiles (red) in time at four locations along the channel (P1, P2, P3 and P4); L = 320 mm, BR = 0.25, $\Phi=1$. 

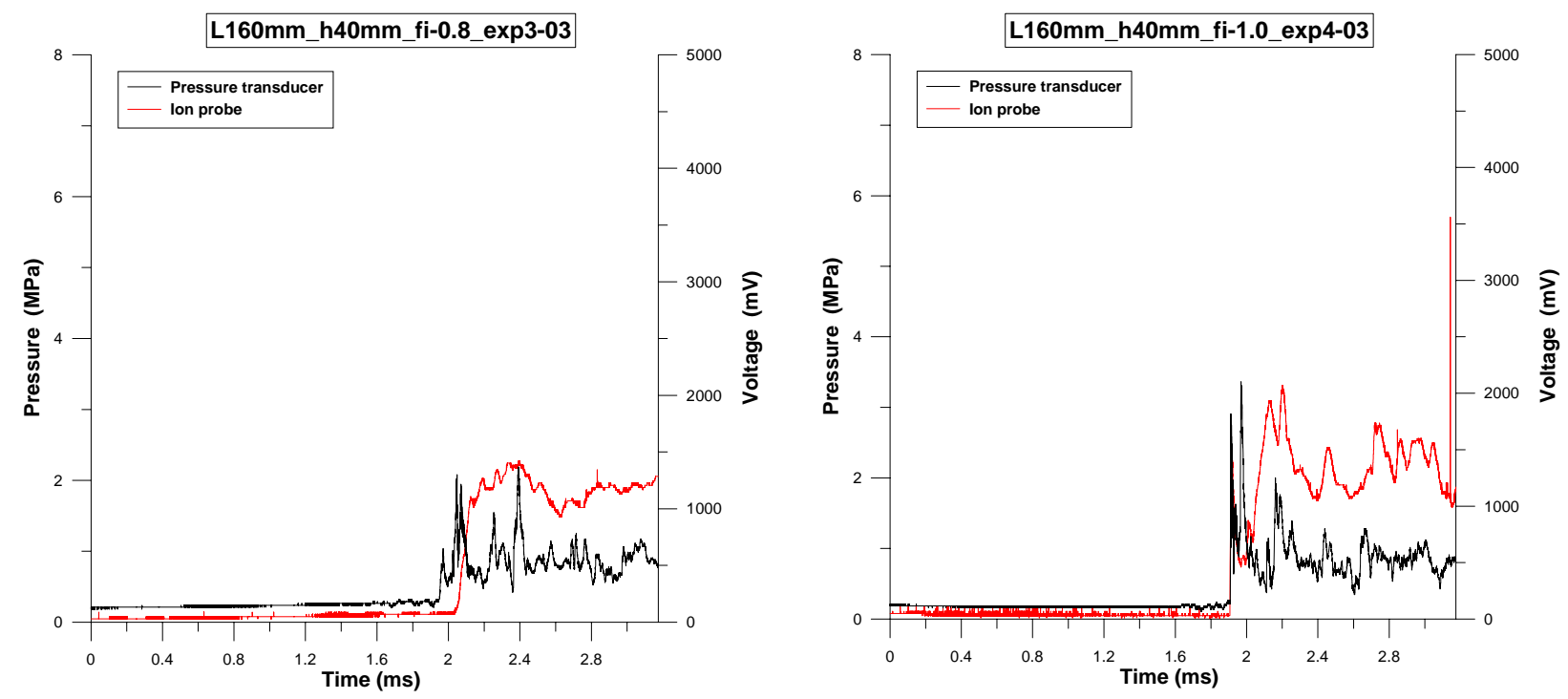

Figure 8. Comparison of pressure profiles (black) and ion probe voltage profiles (red) in time at the same location (P3) along the channel for two mixture compositions (left - $\Phi=0.8$ and right $-\Phi=1$ ); $L=$ $160 \mathrm{~mm}, \mathrm{BR}=0.5$.
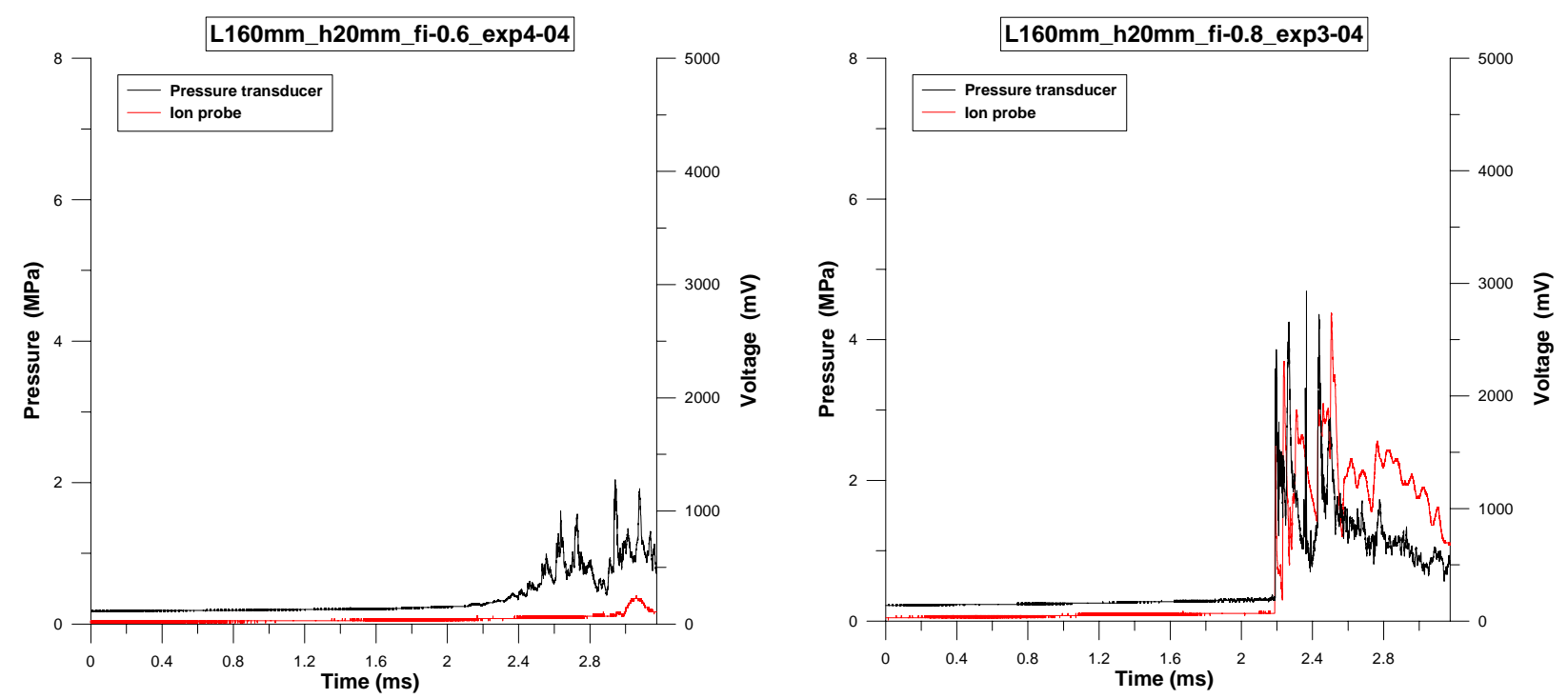

Figure 9. Comparison of pressure profiles (black) and ion probe voltage profiles (red) in time at the same location (P4) along the channel for two mixture compositions (left - $\Phi=0.6$ and right $-\Phi=0.8$ ); $\mathrm{L}=$ $160 \mathrm{~mm}, \mathrm{BR}=0.25$, 


\section{RUN-UP DISTANCE FOR TRANSITION TO DETONATION}

Dorofeev et.al.[18] made an attempt to collect and systematize the experimental data on DDT in obstructed channels in hydrogen-air mixtures. To compare data obtained in channels of different geometries they defined the characteristic dimension for the channel of rectangular cross section:

$$
L_{c h}=\frac{L_{1}}{1-\alpha}
$$

where: $\quad L_{1}=\frac{L+H}{2} \quad$ and $\quad \alpha=\frac{H-h}{H}$

$L$ - distance between obstacles, $H$ - channel height, $h$ - obstacle height.

The values of characteristic dimension $L_{c h}$ calculated for the present study are given in Table 5.

Dorofeev et al. have found the correlation that for successful transition to detonation the characteristic channel dimension must be greater than $7 \lambda$. We found this correlation valid for the results of our study with respect to DDT. However, the correlation also suggests that we should get detonations for more cases, which was not observed in the experiments. Probable reason for that could be not enough length of the channel to reach steady conditions of flame propagation.

Table 5. Characteristic channel dimension $L_{c h}$ for the present study

\begin{tabular}{|l|l|l|l|}
\hline BR & $\mathrm{L}=80 \mathrm{~mm}$ & $\mathrm{~L}=160 \mathrm{~mm}$ & $\mathrm{~L}=320 \mathrm{~mm}$ \\
\hline 0.25 & & $480 \mathrm{~mm}$ & $800 \mathrm{~mm}$ \\
\hline 0.5 & & $240 \mathrm{~mm}$ & $400 \mathrm{~mm}$ \\
\hline 0.75 & $107 \mathrm{~mm}$ & $160 \mathrm{~mm}$ & $267 \mathrm{~mm}$ \\
\hline
\end{tabular}

\section{CONCLUSIONS}

We have presented results of experimental studies of flame propagation regimes and velocities in rectangular cross-section channel with obstacles. Experiments were performed for hydrogen-air mixture for the equivalence ratio $0.6,0.8$ and 1 . Three values of blockage ratio $(0.25,0.5$ and 0.75$)$ and three obstacle densities inside the channel were used.

It was found that obstacles giving high channel blockage ratio are destructive for the flame propagation (large momentum losses) and regardless turbulizing effect they decrease hazard of DDT. The importance of blockage ratio changes with the obstacle density. The higher blockage ratio the larger is optimum obstacle separation distance resulting in highest hazard for DDT. The obstacle density is less important for the lean mixtures $(\Phi=0.6)$ for which no detonation was observed in the experiments.

The predictions were found to be in general agreement with the correlation developed by Dorofeev et al. 


\section{REFERENCES}

1. Dörge ., Pangritz D., Wagner H.G.: On the Influence of Several Orifices on the Propagation of Flames: Continuation of the Experiments of Wheeler. Z.Für Phys.Chemie, 127 (1981), 61-78

2. Moen I.O., Donato M., Knystautas R., Lee J.H.: Flame Acceleration Due to Turbulence Produced by Obstacles. Comb. and Flame, 39 (1980), 21-32

3. Chan C., Moen I.O., Lee J.H.: Influence of Confinement on Flame Acceleration Due to Repeated Obstacles. Comb. and Flame 49 (1983), 27-39

4. Hjertager B.H., Fuhre K., Parker S.J., and Bakke J.R.: Flame Acceleration of Propane-Air in a Large-Scale Obstructed Tube. Dynamics of Shock Waves, Explosions and Detonations. Progress in Astronautics and Aeronautics 94 (1984), pp.504-522

5. Lee J.H., Knystautas R., and Freiman A.: High Speed Turbulent Deflagrations and Transition to Detonation in $\mathrm{H}_{2}$-Air Mixtures. Comb. and Flame 56 (1984), pp.227-239.

6. Teodorczyk A., Lee J.H.S., Knystautas R.: Propagation Mechanism of Quasi-Detonations. Proc.Comb.Inst. 22 (1988), pp.1723-1731.

7. Teodorczyk A., Lee J.H.S., Knystautas R.: The Structure of Fast Turbulent Flames in Very Rough, Obstacle-Filled Channels. Proc..Comb.Inst. 23 (1990), pp.735-741.

8. Teodorczyk A., Lee J.H.S., Knystautas R.: Photographic Study of the Structure and Propagation Mechanisms of Quasi-Detonations in Rough Tubes. Progress in Astronautics and Aeronautics, 133 (1990), pp.223-240.

9. Teodorczyk A., Fast Deflagrations and Detonations in Obstacle-Filled Channels, Biuletyn Instytutu Techniki Cieplnej Politechniki Warszawskiej 79 (1995), pp.145-178

10. Kuznetsov M.S., Alekseev V.I., Dorofeev S.B., Comparison of critical conditions for DDT in regular and irregular cellular detonation systems, Shock Waves 10 (2000), pp.217-223

11. Dorofeev S.B., Kuznetsov M.S., Alekseev V.I., Evaluation of limits for effective flame acceleration in hydrogen mixtures, Journal of Loss Prevention in the Process Industries 14 (2001), pp.583-589.

12. Alekseev V.I., Kuznetsov M.S., Yankin Y.G., Experimental study of flame acceleration and the deflagration-to-detonation transition under conditions of transverse venting, Journal of Loss Prevention in the Process Industries 14 (2001) pp.591-596.

13. Veser A. Breitung W., Dorofeev S.B., Run-up distances to supersonic flames in obstacle-laden tubes, Journal de Physique IV 12 (2002), pp.3-10

14. Kuznetsov M.S., Alekseev V.I., Yankin Y.G. and Dorofeev S.B., Slow and Fast Deflagrations in Hydrocarbon-air Mixtures, Combust. Sci. Tech.174, No.5 (2002), pp.157-172

15. Gamezo V.N., Ogawa T., Oran E.S., Numerical Simulation of Flame Propagation and DDT in Obstructed Channels Filled with Hydrogen-Air Mixture, Proc. Comb. Institute 31 (2007), pp.

16. Reynolds W., The Element Potential Method for Chemical Equilibrium Analysis: Implementation in the Interactive Program STANJAN, M.E.Dept., Stanford University 1986

17. Shepherd J., Kaneshige M., Teodorczyk A., Detonation Database, Caltech 1998, www.galcit.caltech.edu

18. Kuznetsov M.S., Dorofeev S.B., Sidirov V.P., Matsukov I.D., Alekseev V.I., Effect of scale on the onset of detonation. Shock Waves. 10 (2000)., pp.137-149 